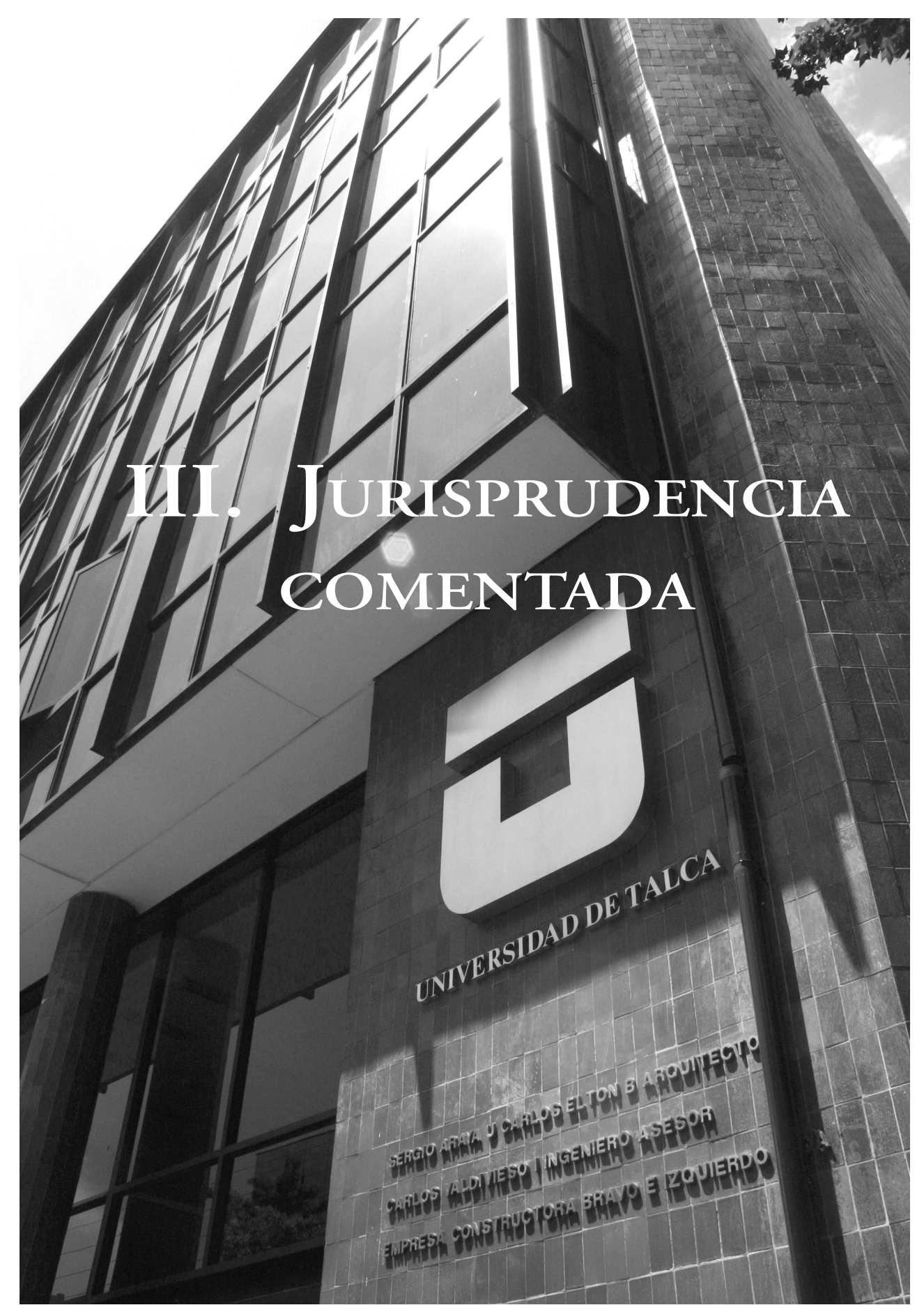



Estudios Constitucionales, Año 11, No 2, 2013, pp. 713 - 736.

ISSN 07180195

Centro de Estudios Constitucionales de Chile Universidad de Talca

"Reflexiones sobre el derecho al recurso a partir de la sentencia 'Mohamed vs. Argentina'

de la Corte Interamericana de Derechos Humanos: Cuestiones a tener en consideración sobre el sistema recursivo en el Proyecto de Código Procesal Civil"

Williams Valenzuela Villalobos

\title{
REFLEXIONES SOBRE EL DERECHO AL RECURSO A PARTIR DE LA SENTENCIA "MOHAMED VS. ARGENTINA" DE LA CORTE INTERAMERICANA DE DERECHOS HUMANOS: CUESTIONES A TENER EN CONSIDERACIÓN SOBRE EL SISTEMA RECURSIVO EN EL PROYECTO DE CÓDIGO PROCESAL CIVIL*
}

\author{
Williams Valenzuela Villalobos** \\ Universidad Mayor - Chile \\ williams.valenzuela@umayor.cl
}

\section{Resumen de la Sentencia de la Corte InTeramericana ReCaída \\ en el Caso "Mohamed vs. Argentina” 1}

Corte Interamericana de Derechos Humanos ${ }^{2}$

Caso Mohamed vs. Argentina

RESUMEN OFICIAL EMITIDO POR LA CORTE INTERAMERICANA

Sentencia de 23 de nOVIEMBRE DE 2012

(Excepción Preliminar, Fondo, Reparaciones y Costas)

El 23 de noviembre de 2012 la Corte Interamericana de Derechos Humanos (en adelante "la Corte Interamericana", "la Corte" o "el Tribunal") emitió la Sentencia, en la cual desestimó la excepción preliminar interpuesta por el Estado, y

\footnotetext{
* Trabajo recibido el 26 de marzo y aprobado el 24 de julio de 2013.

** Licenciado en Ciencias Jurídicas de la Universidad de Talca; Abogado; Magíster (c) en Derecho Constitucional de la misma Universidad (CECOCH). Profesor de Derecho Procesal e Investigador del Centro de Estudios Constitucionales y Administrativos de la Universidad Mayor.

1 Versión completa del fallo [fecha de consulta: 2 de febrero de 2013]. Disponible en: http://www.corteidh. or.cr/docs/casos/articulos/seriec_255_esp.pdf.

2 Integrada por los siguientes Jueces: Diego García-Sayán, Presidente; Manuel E. Ventura Robles, Vicepresidente; Margarette May Macaulay; Rhadys Abreu Blondet; Alberto Pérez Pérez y Eduardo Vio Grossi. El Juez Leonardo A. Franco, de nacionalidad argentina, no participó en el presente caso de conformidad con el artículo 19.1 del Reglamento de la Corte. Presentes, además, el Secretario del Tribunal Pablo Saavedra Alessandri y la Secretaria Adjunta Emilia Segares Rodríguez. El Juez Pérez Pérez hizo conocer a la Corte su Voto Disidente, el cual acompaña la Sentencia.
} 
declaró, por unanimidad, que el Estado es internacionalmente responsable por haber violado el derecho a recurrir del fallo, consagrado en el artículo 8.2.h de la Convención Americana sobre Derechos Humanos, en relación con los artículos 1.1 y 2 de dicho tratado, en perjuicio de Óscar Alberto Mohamed. La Corte determinó la responsabilidad internacional del Estado por no haber garantizado al señor Óscar Alberto Mohamed el derecho a recurrir del fallo penal condenatorio. El señor Mohamed fue condenado como autor del delito de homicidio culposo mediante sentencia emitida el 22 de febrero de 1995 por el tribunal en segunda instancia, la cual revocó el fallo absolutorio que había proferido el juzgado de primera instancia.

\section{Excepción Preliminar}

El Estado interpuso una excepción preliminar solicitando que se rechacen las alegaciones de los representantes de la presunta víctima relativas a la violación del derecho protegido en el artículo 8.4 de la Convención Americana debido a que la estaban invocando "por primera vez en el presente proceso internacional", con lo cual se habría negado a Argentina la oportunidad de darle tratamiento y debida respuesta de acuerdo al carácter subsidiario del derecho internacional.

La Corte reiteró su jurisprudencia constante en la cual ha establecido que las presuntas víctimas y sus representantes pueden invocar la violación de otros derechos distintos a los comprendidos en el informe de fondo, siempre y cuando se atengan a los hechos contenidos en dicho documento. En el presente caso, los representantes alegan la violación al principio de ne bis in idem argumentando que permitir la apelación de la sentencia de absolución a una parte distinta al imputado, es permitir una doble persecución que vulnera dicho principio. El Tribunal constató que esa supuesta violación al artículo 8.4 de la Convención está relacionada con los mismos hechos planteados por la Comisión en el Informe de Fondo, constituidos por las sentencias emitidas en el proceso penal seguido contra el señor Mohamed, pero calificándolos como una supuesta violación del principio de ne bis idem. Consecuentemente, la Corte desestimó la excepción preliminar interpuesta por el Estado.

\section{Fondo}

\section{A. Sintesis de los hechos del caso}

El 16 de marzo de 1992 el señor Óscar Alberto Mohamed, quien trabajaba en la ciudad de Buenos Aires como conductor de una línea de colectivos, fue parte 
de un accidente de tránsito. El señor Mohamed atropelló a una señora, quien sufrió graves lesiones y falleció.

Ese mismo día se inició un proceso penal contra el señor Mohamed por el delito de homicidio culposo. El régimen procesal penal aplicado al señor Mohamed en el proceso penal en su contra fue el regido por el Código de Procedimientos en Materia Penal de 1888, con sus respectivas modificaciones. El Fiscal Nacional de Primera Instancia en lo Criminal y Correccional No 14 presentó acusación contra el señor Mohamed como autor penalmente responsable del delito de homicidio culposo previsto en el artículo 84 del Código Penal. Tanto el fiscal como el abogado del querellante solicitaron que se le impusiera la pena de un año de prisión e inhabilitación especial para conducir por seis años y el pago de las costas procesales.

El 30 de agosto de 1994 el Juzgado Nacional en lo Correccional No 3 emitió sentencia, mediante la cual resolvió, inter alia, absolver a Óscar Alberto Mohamed del delito de homicidio culposo, reprimido en el artículo 84 del Código Penal.

El fiscal del Ministerio Público y el representante del querellante interpusieron recursos de apelación contra los puntos de la sentencia relativos a la absolución y a los honorarios del abogado defensor. El referido juzgado concedió los recursos de apelación y ordenó elevar la causa al superior. El representante del querellante presentó su memorial de expresión de agravios sustentando el recurso de apelación interpuesto. El 22 de febrero de 1995 la Sala Primera de la Cámara Nacional de Apelaciones en lo Criminal y Correccional emitió sentencia, en la cual resolvió, inter alia, condenar al señor Mohamed "por encontrarlo autor penalmente responsable del delito de homicidio culposo a la pena de tres años de prisión, cuyo cumplimiento se deja en suspenso, y a ocho años de inhabilitación especial para conducir cualquier clase de automotor (arts. 26 y 84 del Código Penal)”, e imponer las costas de ambas instancias al condenado.

El ordenamiento jurídico aplicado en el proceso contra el señor Mohamed no preveía ningún recurso penal ordinario para recurrir esa sentencia condenatoria de segunda instancia. El recurso disponible era el recurso extraordinario federal, previsto en el artículo 256 del Código Procesal Civil y Comercial de la Nación.

El 13 de marzo de 1995 el defensor del señor Mohamed interpuso un recurso extraordinario federal contra la sentencia condenatoria ante la misma Sala Primera de la Cámara Nacional de Apelaciones en lo Criminal y Correccional que dictó dicha sentencia, "de conformidad con los arts. 256 y 257 del Código Procesal Civil y Comercial de la Nación” y "con fundamento en los arts. 14 y 15 de la Ley 48 ”. El defensor solicitó a la referida Sala que hiciera lugar al mismo y elevara las 
actuaciones al Superior y que, en la instancia superior, "se disp[usiera] la anulación de la sentencia definitiva [...] ordenándose el dictado de un nuevo fallo conforme a derecho". El defensor del señor Mohamed sostuvo en dicho recurso que se habían afectado garantías constitucionales que habilitaban la vía federal y, entre los motivos de agravio, se refirió a: i) el "defecto en la fundamentación normativa" por haber "busca[do] sustento en una normativa inaplicable al caso" debido a que el decreto citado en el fallo no se encontraba vigente a la fecha del accidente de tránsito; ii) la autocontradicción en la sentencia; iii) haberse prescindido de prueba decisiva; y iv) que el fallo se sustenta "en afirmaciones dogmáticas, que no se compadecen con los hechos ni el derecho".

El 4 de julio de 1995 la referida Sala Primera resolvió "rechazar con costas, el recurso extraordinario", con base, inter alia, en que los argumentos presentados por la defensa "se refieren a cuestiones de hecho, prueba y derecho común, que ha[bían] sido valoradas y debatidas en oportunidad del fallo impugnado". El tribunal también afirmó que: [s]i bien el Tribunal ha incurrido en un error material, al citar [dicho] decreto, que no se hallaba vigente al momento del hecho, el reproche dirigido al procesado se basa en la violación del deber objetivo de cuidado en que éste incurriera, circunstancia que se halla debidamente acreditada en los presentes y que, por otra parte, como se ha referido precedentemente, no es materia de discusión por esta vía.

El 17 de julio de 1995 el señor Mohamed fue despedido de su empleo como chofer de colectivo, en razón de "su inhabilitación penal para conducir".

El 18 de julio de 1995 el defensor del señor Mohamed interpuso un recurso de queja ante la Corte Suprema de Justicia de la Nación "por haberse[1]e denegado el Recurso extraordinario interpuesto contra el fallo definitivo dictado en segunda instancia" y solicitó que se anulara la sentencia recurrida y se ordenara dictar un nuevo fallo. El defensor reiteró su posición sobre la aplicación retroactiva del Decreto 692/92 y señaló que el fallo que rechazó el recurso extraordinario violó el artículo 9 de la Convención Americana. El 19 de septiembre de 1995 la Corte Suprema de Justicia de la Nación "desestim[ó] la queja”, indicando que "el recurso extraordinario, cuya denegación motiva[ba] la [...] queja, [era] inadmisible (art. 280 del Código Procesal Civil y Comercial de la Nación".

El 27 de septiembre de 1995 el defensor del señor Mohamed interpuso un escrito ante la referida Corte Suprema solicitándole que revocara la decisión que desestimó el recurso de queja.

Expuso, entre otros alegatos que, el señor Mohamed "no ha[bía] sido oíd[o] con las garantías debidas" configurándose una violación del artículo 8 de la Con- 
vención Americana sobre Derechos Humanos, así como que al "hab[erse] aplicado retroactivamente una normatividad" la revocatoria de la sentencia absolutoria había violado, entre otros, el artículo 9 de dicha Convención. El 19 de octubre de 1995 la Corte Suprema de Justicia de la Nación desestimó el recurso interpuesto por el defensor del señor Mohamed en tanto "las sentencias del Tribunal no son susceptibles de reposición o revocatoria”.

\section{B. Derecho a las garantías judiciales}

Alegadas violaciones a los artículos 8.2.c, 8.2.d, 8.2.e, 25.2.a y 25.2.b de la Convención Americana

La Corte no se pronunció sobre las alegadas violaciones a los artículos 8.2.d, 8.2.e, 25.2.a y 25.2.b de la Convención Americana, puesto que los representantes no presentaron argumentos de derecho sobre esas alegadas violaciones y ni siquiera refirieron sobre cuáles hechos versarían. El Tribunal tampoco se pronunció sobre la alegada violación al derecho de defensa del señor Mohamed durante el proceso penal seguido en su contra, sostenida únicamente por los representantes, debido a que éstos basaron sus argumentos en normativa procesal penal que no fue aportada al acervo probatorio del presente caso.

\section{Derecho de recurrir del fallo ante un juez o tribunal superior}

En primer término, el Tribunal se pronunció sobre el alcance del artículo 8.2.h de la Convención con respecto a sentencias penales de condena emitidas al resolver un recurso contra la absolución, debido a que el Estado sostuvo que sería permitido establecer excepciones al derecho a recurrir condenas penales. La Corte estableció que el derecho a recurrir del fallo no podría ser efectivo si no se garantiza respecto de todo aquel que es condenado, y que resulta contrario al propósito de ese derecho específico que no sea garantizado frente a quien es condenado mediante una sentencia que revoca una decisión absolutoria. Interpretar lo contrario, implicaría dejar al condenado desprovisto de un recurso contra la condena. La Corte concluyó que, en los términos de la protección que otorga el artículo 8.2.h de la Convención Americana, el señor Mohamed tenía derecho a recurrir del fallo proferido por la Sala Primera de la Cámara Nacional de Apelaciones el 22 de febrero de 1995, toda vez que en éste se le condenó como autor del delito de homicidio culposo.

Seguidamente, la Corte se refirió al contenido de la garantía que otorga el artículo 8.2.h de la Convención. La Corte resaltó que el derecho de impugnar 
el fallo busca proteger el derecho de defensa, y reiteró que el artículo 8.2.h de la Convención se refiere a un recurso ordinario accesible y eficaz, lo cual supone, inter alia, que: debe ser garantizado antes de que la sentencia adquiera la calidad de cosa juzgada; debe procurar resultados o respuestas al fin para el cual fue concebido; y las formalidades requeridas para que el recurso sea admitido deben ser mínimas y no deben constituir un obstáculo para que el recurso cumpla con su fin de examinar y resolver los agravios sustentados por el recurrente.

Asimismo, el Tribunal indicó que, independientemente del régimen o sistema recursivo que adopten los Estados Partes y de la denominación que den al medio de impugnación de la sentencia condenatoria, para que éste sea eficaz debe constituir un medio adecuado para procurar la corrección de una condena errónea. Ello requiere que pueda analizar cuestiones fácticas, probatorias y jurídicas en que se basa la sentencia impugnada. Consecuentemente, las causales de procedencia del recurso deben posibilitar un control amplio de los aspectos impugnados de la sentencia condenatoria. Además el Tribunal consideró que, en la regulación que los Estados desarrollen en sus respectivos regímenes recursivos, deben asegurar que dicho recurso contra la sentencia condenatoria respete las garantías procesales mínimas que, bajo el artículo 8 de la Convención, resulten relevantes y necesarias para resolver los agravios planteados por el recurrente, lo cual no implica que deba realizarse un nuevo juicio oral.

Posteriormente, la Corte analizó si al señor Mohamed se le garantizó el derecho a recurrir del fallo condenatorio. La Corte hizo notar que no fue controvertido que el ordenamiento jurídico aplicado al señor Mohamed no preveía ningún recurso penal ordinario para que aquel pudiera recurrir la sentencia condenatoria que le fue impuesta. La decisión condenatoria de segunda instancia era una sentencia definitiva recurrible solamente a través de un recurso extraordinario federal y un posterior recurso de queja.

La Corte consideró que el referido recurso extraordinario no constituye un medio de impugnación procesal penal, sino que se trata de un recurso extraordinario regulado en el Código Procesal Civil y Comercial de la Nación, el cual tiene sus propios fines en el ordenamiento argentino. Asimismo, resaltó que las causales que condicionan la procedencia de dicho recurso están limitadas a la revisión de cuestiones referidas a la validez de una ley, tratado, norma constitucional o a la arbitrariedad de una sentencia, y excluye las cuestiones fácticas y probatorias, así como de derecho de naturaleza jurídica no constitucional.

No obstante lo anterior y tomando en cuenta que el Estado sostuvo que el recurso extraordinario federal podría haber garantizado el derecho a recurrir del 
fallo condenatorio, la Corte efectuó consideraciones adicionales relativas a examinar el tratamiento que en el caso concreto dieron los órganos judiciales a los recursos interpuestos por el señor Mohamed. La Corte resaltó que, aun cuando se analice si materialmente dichos recursos habrían protegido el derecho a recurrir la sentencia condenatoria del señor Mohamed, las causales de procedencia del recurso extraordinario limitaban per se la posibilidad del señor Mohamed de plantear agravios que implicaran un examen amplio y eficaz del fallo condenatorio. Por consiguiente, tal limitación incide negativamente en la efectividad que en la práctica podría tener dicho recurso para impugnar la sentencia condenatoria.

La Corte constató que en el presente caso el alcance limitado del recurso extraordinario federal quedó manifiesto en la decisión proferida por la Sala Primera de la Cámara Nacional de Apelaciones, la cual rechazó in limine el recurso interpuesto por el defensor del señor Mohamed con base en que los argumentos presentados se referían "a cuestiones de hecho, prueba y derecho común, que ha[bían] sido valoradas y debatidas en oportunidad del fallo impugnado".

La Corte concluyó que el sistema procesal penal argentino que fue aplicado al señor Mohamed no garantizó normativamente un recurso ordinario accesible y eficaz que permitiera un examen de la sentencia condenatoria contra el señor Mohamed, en los términos del artículo 8.2.h de la Convención Americana, y también constató que el recurso extraordinario federal y el recurso de queja no constituyeron en el caso concreto recursos eficaces para garantizar dicho derecho.

Adicionalmente, la Corte concluyó que la inexistencia de un recurso judicial que garantizara la revisión de la sentencia de condena del señor Mohamed y la aplicación de unos recursos judiciales que tampoco garantizaron tal derecho a recurrir del fallo implicaron un incumplimiento del Estado del deber general de adecuar su ordenamiento jurídico interno para asegurar la realización de la garantía judicial protegida por el artículo 8.2.h de la Convención.

Con base en las anteriores consideraciones, la Corte determinó que Argentina violó el derecho a recurrir del fallo protegido en el artículo 8.2.h de la Convención Americana, en relación con los artículos 1.1 y 2 de dicho tratado, en perjuicio del señor Óscar Alberto Mohamed.

Alegadas violaciones a los artículos 8.1, 8.2.c y 25.1 de la Convención Americana

La Corte no estimó necesario realizar un pronunciamiento adicional sobre las alegadas violaciones al derecho de defensa, al derecho a ser oído, al deber de motivar y al derecho a un recurso sencillo, rápido y efectivo, supuestamente derivadas de las decisiones judiciales emitidas por la Sala Primera de la Cámara y 
por la Corte Suprema de Justicia de la Nación al resolver sobre la inadmisibilidad del recurso extraordinario federal y del recurso de queja, debido a que consideró que las alegadas afectaciones que hubiere sufrido el señor Mohamed debido a esas decisiones judiciales quedan comprendidas dentro de la violación al derecho a recurrir del fallo.

Alegada violación al derecho protegido en el artículo 8.4 de la Convención Americana

En cuanto a los alegatos de los representantes de que en Argentina se ha desarrollado un "estándar [...] más protector de derechos que el que surgiría de una interpretación literal del texto del artículo 8.4 de la Convención”, el Tribunal indicó que no fue probado que en Argentina el principio de ne bis in idem está jurídicamente protegido y debe ser garantizado de forma más amplia que en los términos indicados en la Convención. Por lo tanto, la Corte no analizó lo solicitado por los representantes en cuanto al criterio de interpretación del artículo 29.b) de la Convención.

La Corte reiteró que el principio ne bis in idem, consagrado en el artículo 8.4 de la Convención, se sustenta en la prohibición de un nuevo juicio sobre los mismos hechos que han sido materia de la sentencia dotada con autoridad de cosa juzgada. La Corte consideró que el señor Mohamed no fue sometido a dos juicios o procesos judiciales distintos sustentados en los mismos hechos. La sentencia condenatoria del señor Mohamed no se produjo en un nuevo juicio posterior a una sentencia firme que hubiera adquirido la autoridad de la cosa juzgada, sino que fue emitida en una etapa de un mismo proceso judicial penal. Por consiguiente, la Corte concluyó que el Estado no violó el artículo 8.4 de la Convención en perjuicio del señor Óscar Alberto Mohamed.

\section{Alegada violación al principio de legalidad}

En el presente caso el señor Mohamed fue condenado como autor del delito de homicidio culposo tipificado en el artículo 84 del Código Penal vigente al momento del hecho (accidente de tránsito). La Comisión y los representantes alegaron que se produjo una violación al principio de irretroactividad porque el tribunal integró el referido tipo penal con las normas del Decreto No 692/92 reglamentario del tránsito automotor que entró en vigencia con posterioridad al hecho.

El Tribunal hizo notar que tratándose de un delito culposo, cuyo tipo penal es abierto y requiere ser completado por el juzgador al realizar el análisis de la tipici- 
dad, lo relevante es que en la sentencia se individualice el correspondiente deber de cuidado infringido con la conducta activa (imprudencia) u omisiva (negligencia) del imputado y que ello fuera determinante para que se produjera el resultado lesivo del bien jurídico tutelado. La Corte constató que entre los fundamentos de la sentencia condenatoria para individualizar el "deber de cuidado" exigible al imputado, se hizo referencia, por una parte, a las "[l] as normas de cuidado" aplicables al caso como "normas de práctica internacional" y, por la otra, a "principios" de tales prácticas contenidos en un reglamento de tránsito (Decreto Ley No 692/92) que aún no había entrado en vigencia al momento del hecho.

La Corte consideró que las cuestiones planteadas tratan asuntos penales que corresponde sean examinados por el tribunal superior que debe conocer del recurso contra el fallo condenatorio del señor Mohamed. Por ende, la Corte no estimó pertinente determinar si las consideraciones relativas a los fundamentos jurídicos de la sentencia condenatoria para completar el tipo penal de homicidio culposo implican o no una vulneración del artículo 9 de la Convención.

\section{Reparaciones}

La Corte estableció que su Sentencia constituye per se una forma de reparación y, adicionalmente, ordenó al Estado las siguientes reparaciones: (i) adoptar las medidas necesarias para garantizar al señor Óscar Alberto Mohamed el derecho a recurrir del fallo condenatorio, de conformidad con los parámetros convencionales establecidos en el artículo 8.2.h de la Convención Americana; (ii) adoptar las medidas necesarias para que los efectos jurídicos de referida sentencia condenatoria, $\mathrm{y}$ en especial su registro de antecedentes, queden en suspenso hasta que se emita una decisión de fondo garantizando el derecho del señor Óscar Alberto Mohamed a recurrir del fallo condenatorio; (iii) publicar, en un plazo de seis meses, contado a partir de la notificación de la presente Sentencia: a) el resumen oficial de la presente Sentencia elaborado por la Corte, por una sola vez en el Diario Oficial; b) el resumen oficial de la presente Sentencia elaborado por la Corte, por una sola vez, en un diario de amplia circulación nacional, y c) la presente Sentencia en su integridad, disponible por un período de un año, en un sitio web oficial; (iv) pagar las cantidades fijadas en la Sentencia por concepto de indemnización por daño material e inmaterial, y por el reintegro de costas y gastos, así como reintegrar al Fondo de Asistencia Legal de Víctimas de la Corte Interamericana la cantidad establecida en la Sentencia.

El Tribunal dispuso que Argentina debe rendir, dentro del plazo de un año, contado a partir de la notificación de la Sentencia, un informe sobre las medidas 
adoptadas para cumplir con la misma. La Corte supervisará el cumplimiento íntegro de la Sentencia, en ejercicio de sus atribuciones y en cumplimiento de sus deberes conforme a la Convención Americana sobre Derechos Humanos, y dará por concluido el presente caso una vez que el Estado haya dado cabal cumplimiento a lo dispuesto en la misma.

\section{REFLEXIONES A PARTIR DEL FALLO}

\section{A. La oralidad en el Proyecto de Código Procesal Civil}

Es sabido por todos que en Chile, desde marzo de 2012, se encuentra en discusión legislativa un Proyecto de Código Procesal Civil (Boletín No 8197-07) que viene a sustituir el actual Código del ramo y, en definitiva, a cambiar el modelo de enjuiciamiento; instaurándose un nuevo proceso con rasgos claramente definidos: oral, concentrado, con inmediación judicial efectiva, público y ampliando las facultades materiales del juez, entre otras características, que perfilarían el nuevo proceso civil.

Ahora bien, demás está decirlo, la reforma procesal civil apuntó y siguió el camino preestablecido por las reformas procesales anteriores (penal, de familia y laboral) instituyendo un modelo cuya centralidad del sistema se encuentra en la preeminencia del juicio oral desarrollado por audiencias (una única, o dos o más audiencias próximas). Así, se ha venido siguiendo una tónica mundial de dar preponderancia a la regla de la oralidad (desechándose en principio la contribución de la regla de la escrituración). Si bien es cierto, la decisión legislativa de optar por una u otra regla del debate viene acompañada de las consecuencias ${ }^{3}$ u objetivos que se quieren lograr en aras de modernizar la justicia y dar respuestas de calidad que en mayor medida se legitimen per se, no se puede dejar de señalar que en nuestro medio se ha venido exagerando el rol y función que se le ha atribuido a la oralidad, lo que ha llevado a excesos que no podemos tolerar.

En dicha línea, se ha propagado con fuerza la idea que el proceso (como mecanismo heterocompisitivo de solución de conflictos y que posibilita la aplicación del Derecho material) cumpliría su función de mejor manera en la medida que

3 En efecto, se señala que la regla de la oralidad trae aparejadas como consecuencia los principios de inmediación judicial, publicidad real de los actos procesales y la concentración. Por su lado, la regla de la escrituración se asocia a la mediación, la nula publicidad de los actos procesales y la desconcentración. 
fuese oral ${ }^{4}$, ya que se privilegia el control horizontal por sobre el vertical, facilita la decisión de mérito del asunto controvertido (el juez percibe la prueba directamente, sin intermediarios) y permite el desarrollo de un proceso concentrado, sin dilaciones excesivas, como las que usualmente se conocen en el mundo procesal civil.

El descarte prima facie de la contribución de la regla de la escrituración nos debe llamar la atención. Las reglas del debate, usualmente establecidas en forma dual $^{5}$, no representan opciones del todo o nada, el legislador debe ser lo suficientemente sabio e informado para efectos de determinar dónde y cuándo es mejor emplearlas. En efecto, el proceso de familia (y en general la mayoría de los procesos orales) contemplan una fase de discusión escrita que facilita la exposición del pleito y permite que de mejor forma se determine el objeto del juicio. Así, nos enfrentamos a prevalecimientos, no a exclusividades: no existen procesos absolutamente orales o puramente escritos ${ }^{6}$. Apuntada dicha idea, ahora cabe señalar que en la configuración legislativa, fuera de estas reglas del debate o reglas técnicas procesales encontramos otros elementos o piezas ${ }^{7}$ que son indisponibles para el legislador y que su ausencia nos enfrenta a un no-proceso, es decir, son elementos esenciales, que todo proceso debe poseer para permitir la solución real y efectiva del conflicto.

Los elementos o piezas a que aludíamos representan las garantías (o postulados de justicia) que conforman el racional y justo procedimiento (proceso) a que alude nuestra Constitución Política en el inciso $6^{\circ}$ del numeral $3^{\circ}$ del artículo $19^{\circ}$. Entre ellos encontramos el derecho a la defensa, la igualdad de armas, el derecho a la prueba, la obtención de respuestas jurisdiccionales en un plazo razonable, la bilateralidad de la audiencia, entre otros. En dicha línea Humberto Nogueira nos dice que el debido proceso "considera como mínimo el emplazamiento, el dere-

\footnotetext{
4 Agregan algunos autores de forma crítica: "Otros sostienen que el proceso oral permite también una mejor justicia, pues el juez puede ver directamente a las partes y a los testigos del juicio, todo lo cual ayudaría de mejor modo a formar su convicción" (BORDALí; HunTer (2010) [fecha de consulta: 25 de marzo de 2013]. Disponible en: http://www.microjuris.cl).

5 GonzAlez (2004), p. 288.

6 "Así, pues oralidad y escritura, en vez de oralidad contra escritura". Notable es la apreciación anterior y lo razonable del planteamiento que clarifica y pone en el lugar que corresponde dichas reglas técnicas puntualizando la necesidad, dependiendo del fin deseado, de estructurar las diversas fases del procedimiento con predominio de una u otra (De la Oliva, 2009, p. 65).

7 Así señala Palomo Vélez: "El proceso es una realidad artificial que el legislador procesal construye recurriendo a distintas "piezas" (Palomo, 2010, p. 471).
} 
cho de defensa letrada, la bilateralidad y principio de contradicción, el dictar la sentencia en un plazo razonable por un tribunal que tenga el carácter de objetivo e imparcial" 8 . Asimismo, Adolfo Alvarado Velloso9 señala que estos principios se reducen sólo a cinco: la igualdad de las partes litigantes, la imparcialidad del juzgador, la transitoriedad de la serie, la efectividad de la serie y la moralidad del debate.

Así, establecido claramente que en la configuración de un proceso entran en juego elementos indisponibles y otros que libremente el legislador puede utilizar o prescindir de ellos, es necesario asentar ahora la idea que la ausencia de los verdaderos principios del proceso acarrea necesariamente consecuencias perniciosas para los derechos del justiciable y, por el contrario, la utilización o no de las reglas del debate (o su empleo en forma mixta) no genera consecuencias de ninguna índole en dicha faz, ya que representan la cara externa del proceso, sólo su forma de desarrollo.

En síntesis, la oralidad es una regla técnica procesal, que como tal es de libre utilización por el legislador y representa una forma de desarrollar el proceso por medio de la palabra hablada.

\section{B. El derecho a recurrir de un fallo ante un juez o tribunal superior: Derecho al Recurso}

En base a erradas premisas se ha venido sosteniendo, ya desde la reforma procesal penal, que el juicio oral debe primar por sobre la posibilidad de alzarse en contra de un fallo agraviante. Tras dicha afirmación subyacen las ideas centrales de este comentario: de una parte, la delimitación y alcances del derecho al recurso (y su aplicación a materias civiles) y, de la otra, la compatibilidad de los modelos orales con sistemas recursivos amplios.

El derecho al recurso o derecho a recurrir de un fallo ante un tribunal superior, igualmente independientes e imparcial, viene impuesto desde nuestra propia Constitución Política de la República, como una garantía del racional y justo proceso, que deriva de la aplicación de los principios favor persona y de progresividad en materia de interpretación de derechos humanos, ya que los derechos normonológicamente recogidos en tratados internacionales, vigentes y válidamente incorporados al derecho interno, limitan el ejercicio de la soberanía estatal (artículo

8 Nogueira (2008), p. 264.

9 GonZález (2004), p. 287. 
$5^{\circ}$ inciso $2^{\circ}$ de la CPR) e imponen la obligación a todos los agentes del Estado no sólo de respetarlos y asegurarlos, sino que de promoverlos. En efecto, el derecho que venimos reclamando encuentra consagración expresa en el artículo 8.2.h. de la Convención Americana de Derechos Humanos (CADH) y en el artículo 14.5 del Pacto Internacional de Derechos Civiles y Políticos (PIDCP).

El señalado artículo $8^{\circ}$ (Garantías Judiciales) de la Convención señala, en su parte pertinente:

"2. Toda persona inculpada de delito tiene derecho a que se presuma su inocencia mientras no se establezca legalmente su culpabilidad. Durante el proceso, toda persona tiene derecho, en plena igualdad, a las siguientes garantías minimas: h) derecho de recurrir del fallo ante juez o tribunal superior".

Por su parte, el artículo 14 del Pacto señala:

"5. Toda persona declarada culpable de un delito tendrá derecho a que el fallo condenatorio y la pena que se le haya impuesto sean sometidos a un tribunal superior, conforme a lo prescrito por la ley".

Consagrada la existencia del derecho al recurso, es menester ahora señalar su contenido o delimitación, el que puede ser sistematizado a partir del fallo y de la jurisprudencia anterior de la Corte Interamericana. Así, el derecho comprende:

i. La existencia de arbitrios procesales para ante un tribunal superior, que permitan alzarse contra las resoluciones agraviantes para al justiciable;

ii. Los arbitrios procesales son de libre configuración por los legisladores nacionales, en lo que dice relación a los plazos, requisitos formales o nomen iuris que se le atribuya a los mismos, y

iii. El recurso libremente configurado por el legislador, debe permitir alzarse contra ambos errores que puede cometer la jurisdicción: de hecho y de derecho, es decir, debe permitir un examen integral de todas las cuestiones fácticas, probatorias y jurídicas ${ }^{10}$, debatidas y analizadas por el tribunal inferior; debiendo reunir el arbitrio las cualidades de ser un recurso sencillo, ordinario, eficaz y accesible.

Del contenido antes enunciado el más complejo de abordar, y que nos conecta con la idea de la compatibilidad de un recurso amplio con un sistema oral, es el tercero, es decir, que el recurso debe ser amplio y permitir impugnar la resolución

10 Sentencia de la Corte Interamericana de Derechos Humanos, de 23 noviembre de 2012. Serie C No 255,

"Mohamed vs. Argentina", párrafo No 100. 
judicial agraviante en toda su extensión, tanto en los hechos como el derecho, para disminuir la posibilidad de error y de arbitrariedad del juzgador.

En Chile se impuso (o mejor dicho se autoimpuso) la idea de la incompatibilidad absoluta de un recurso amplio (como el de apelación) con la posibilidad de impugnar una respuesta jurisdiccional obtenida de un proceso oral. Se resguarda así el juicio y la sentencia, prácticamente blindando la respuesta jurisdiccional, por ser obtenida de un proceso oral, donde el juez ha presenciado personalmente la práctica probatoria y ha observado y controlado el ingreso del material fáctico al proceso. La decisión de mérito así obtenida escapa al control que el tribunal superior pueda efectuar de ella: el tribunal ad quem no se encuentra en el grado de proximidad con que el juez a quo obtuvo la decisión, por tanto, ello es incontrolable.

Así se abogó (salvo en la reforma de familia) por el establecimiento de "novedosos" recursos que permitieran respetar la oralidad y la inmediación judicial. En efecto, se crearon los recursos de nulidad penal y nulidad laboral, que apuntan al control de la juridicidad de lo resuelto, resguardando la aplicación e interpretación del Derecho material (nomofilaxis ${ }^{11}$ ) y, por defecto, la obra creadora de Derecho del legislador. Dichos arbitrios representan medios de control que permiten al justiciable alzarse sólo por alguna de las causales taxativamente establecidas en la ley, tornando a los recurso en medios extraordinarios de impugnación, donde además por casi aplicación sacra del principio de intangibilidad de los hechos (propio de la casación) la posibilidad de control fáctico se reduce a un mínimum, que claramente no satisface el contenido esencial del derecho al recurrir ${ }^{12}$.

11 "Sin lugar a dudas, un recurso entendido como garantía no puede solamente limitarse a un análisis de tipo nomofiláctico, o en protección de mera legalidad”. GONZÁLEZ (2004), p. 191.

12 Se ha dicho respecto del recurso de nulidad laboral y la determinación de los hechos: "La determinación del factum del pleito quedó de este modo entregado -en exclusiva- al juez, sin perjuicio de las eventuales 'rendijas' que ofrecería la regulación del recurso de nulidad laboral a partir de una causal en particular", agregándose que "Nos referimos a la causal siguiente: cuando haya sido pronunciada (la sentencia) con infracción manifiesta de las normas sobre la apreciación de la prueba conforme a las reglas de la sana crítica. Sin embargo, tales rendijas, desde la visión idealizada y desbordada que ha caracterizado a la inmediación judicial y las consecuencias que se han asignado al carácter extraordinario que se reconoce en el recurso de nulidad, han quedado muchas veces cerradas en el marco de una realidad jurisprudencial que además de destacar la calidad extraordinaria y de derecho estricto del recurso, advierte repetidamente que a través de este mecanismo de impugnación no es posible inmiscuirse en las cuestiones de hecho establecidas por el tribunal de la instancia, impedimento que encuentra justificación (según se lee de las propias sentencias) en el hecho de que frustraría la finalidad misma para la que fue instaurada la inmediación, perdiéndose la posición privilegiada del juez del juicio oral respecto del tribunal de alzada, transformándose el recurso en cuestión en una nueva instancia" (Palomo; Valenzuela, 2011, p. 400 y cita No 2). 
El juicio oral y la inmediación judicial deben ceder ante la garantía del derecho al recurso y no al revés, como señala Luigi Ferrajoli: "es el precio que se debe pagar por el valor de la doble instancia, si queremos salvar la esencial función garantista"13. En efecto, el fallo señala "debe entenderse que, independientemente del régimen o sistema recursivo que adopten los Estados Partes y de la denominación que den al medio de impugnación de la sentencia condenatoria, para que éste sea eficaz debe constituir un medio adecuado para procurar la corrección de una condena errónea. Ello requiere que pueda analizar cuestiones fácticas, probatorias y jurídicas en que se basa la sentencia impugnada, puesto que en la actividad jurisdiccional existe una interdependencia entre las determinaciones fácticas y la aplicación del derecho, de forma tal que una errónea determinación de los hechos implica una errada o indebida aplicación del derecho. Consecuentemente, las causales de procedencia del recurso deben posibilitar un control amplio de los aspectos impugnados de la sentencia condenatoria" 14 .

Los Corte Interamericana de esta forma reafirma, consolidando una jurisprudencia ya constante sobre el derecho al recurso ${ }^{15}$, la idea de que el medio de impugnación debe ser eficaz y permitir controlar las cuestiones fácticas, probatorias y jurídicas. Si aplicamos sólo dichos dos parámetros a los recursos de nulidad enunciados, claramente nos vemos enfrentados a la posible responsabilidad internacional de nuestro Estado por violación de derechos humanos, ya que el recurso no será eficaz en la medida que contemple taxativas causales que, además, limitan la posibilidad de control amplio, es decir (en palabras de la Corte) dichas causales taxativas "limitaban per se la posibilidad del señor Mohamed de plantear agravios que implicaran un examen amplio y eficaz del fallo condenatorio. Por consiguiente, se debe tomar en cuenta que tal limitación incide negativamente en la efectividad que en la práctica podría tener dicho recurso para impugnar la sentencia condenatoria" 16.

Además, es necesario señalar que las garantías del derecho al recurso son plenamente aplicables a materias civiles. En consecuencia, el contenido y delimitación del derecho al recurso ha sido desarrollado principalmente en sede penal, como una garantía que le asiste al imputado en el marco de un proceso punitivo, pero

\footnotetext{
13 Ferrajoli, Luigi citado por GonZález (2004), p. 303.

14 Sentencia de la Corte Interamericana de Derechos Humanos, de 23 noviembre de 2012. Serie C No 255, "Mohamed vs. Argentina", párrafo No 1000.

15 Ver, entre otras, Sentencia de la Corte Interamericana de Derechos Humanos, de 2 julio de 2007. Serie C No 107, "Herrera Ulloa vs. Costa Rica".

16 Sentencia de la Corte Interamericana de Derechos Humanos, de 23 noviembre de 2012. Serie C No 255, "Mohamed vs. Argentina", párrafo No 106.
} 
el derecho al recurso como elemento del debido proceso constitucional, recibe plena aplicación en los procedimientos de naturaleza civil, laboral, fiscal o de cualquier otro orden. El debido proceso es uno y sus garantías se deben aplicar a todo proceso independiente del objeto del mismo, ya que las exigencias mínimas que reclama son en interés del justiciable y no del juez o tribunal, por ello, en una interpretación armónica del texto constitucional y por imposición del postulado favor persona, su contenido es exigible en jurisdicciones extrapenales.

En consideración a lo anterior, "un proceso debe ser debido o justo independientemente de si lo que se discute ha sido definido como penal, laboral, familiar o comercial"17, en consecuencia, los tratados internacionales asumen "la idea de que todo proceso debe satisfacer el piso básico descrito"18. Recuérdese (como señalábamos) que el proceso es uno a través de sus diversas etapas y, asimismo, "todo proceso debe ganarse el nombre de debido y el apellido de justo"19.

La doctrina ha señalado expresamente que el derecho al recurso cuya fuente formal (principal en el ámbito regional) es el artículo 8.2.h. de la CADH recibe aplicación a todo proceso. Así, las garantías del numeral 2 del artículo $8^{\circ}$ se entiende aplicable a dichas cuestiones, incluso, por una interpretación literalista, donde encontramos dos frases separadas claramente por un punto ${ }^{20}$ : "Este numeral comienza diciendo 'toda persona inculpada de delito...', tras lo cual consagra explícitamente el estado de inocencia, el que se ha formulado siempre desde la óptica penalista. La segunda oración del numeral 2 prescribe que 'durante el proceso toda persona...', desapareciendo la expresión 'inculpada de delito', reforzando que goza de estas garantías mínimas 'toda persona”" 21 . Con lo cual se ha querido poner de relieve que los literales del mencionado numeral 2 del artículo $8^{\circ}$ son aplicables a toda persona y en todo procedimiento prescindiendo de una interpretación restrictiva ${ }^{22}$.

Encuentra además sustento la tesis que venimos sosteniendo en la propia jurisprudencia de la Corte Interamericana quien ha dicho: "Ya la Corte ha dejado

17 Duce; Marín; Riego (2008), p. 30.

18 Duce; Marín; Riego (2008), p. 30.

19 Colombo (2006), p. 89.

20 GonZÁlez (2004), pp. 268 y ss.

21 Cita No 187 en Palomo (2010), pp. 500-501.

22 Si dichas garantías mínimas del numeral 2 del artículo $8^{\circ}$ de la $\mathrm{CADH}$ fueren sólo aplicables al proceso penal, cómo se explicaría la existencia de los numerales 3 y 4 que consagran también garantías de tipo penal. Cita No 187 en Palomo (2010), pp. 500-501. 
establecido que a pesar de que el citado artículo $\left(8^{\circ}\right)$ no especifica garantías minimas en materias que conciernen a la determinación de los derechos y obligaciones de orden civil, laboral, fiscal o de cualquier otro carácter, el elenco de garantías minimas establecido en el numeral 2 del mismo precepto se aplica también a esos órdenes y, por ende, en ese tipo de materias el individuo tiene también el derecho, en general, al debido proceso que se aplica en materia penal' 23 . No cabe duda, salvo interpretaciones obtusas, que las garantías del debido proceso (compresivas del derecho al recurso) son aplicables a todo proceso, independiente de la materia que sea objeto el pleito.

Para cerrar, cabe referirse brevemente a la jurisprudencia de nuestro Tribunal Constitucional ${ }^{24}$, que si bien ha reconocido la existencia y ubicación del derecho al recurso dentro de las garantías del debido proceso, no ha aplicado un acertado test de constitucionalidad de las normas impugnadas - principalmente- por vía de inaplicabilidad, que establecen los actuales sistemas recursivos en sede penal y laboral, que fuertemente han sido criticados por la doctrina, por no adecuarse a los estándares que deben reunir los medios impugnación. En efecto, ha señalado la Magistratura Constitucional que "no obstante lo anterior y entrando al fondo del asunto, cabe sostener, en primer lugar, que el derecho al recurso forma parte integrante del derecho al debido proceso. Asi se ha señalado, entre otras sentencias, en los roles

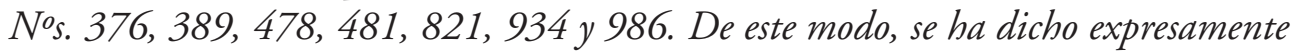
que 'el derecho a un proceso previo, legalmente tramitado, racional y justo, que la Constitución asegura a todas las personas, debe contemplar las siguientes garantías: la publicidad de los actos jurisdiccionales, el derecho a la acción, el oportuno conocimiento de ella por la parte contraria, el emplazamiento, adecuada defensa y asesoría con abogados, la producción libre de pruebas conforme a la ley, el examen y objeción

23 Sentencia de la Corte Interamericana de Derechos Humanos, de 24 de septiembre de 1999. Serie C. No 55, "Tribunal Constitucional vs. Perú", párrafo 70. El agregado es nuestro.

24 Se tuvieron en consideración los siguientes fallos: Rol No 821: Requerimiento de inaplicabilidad por inconstitucionalidad respecto del artículo 387, inciso segundo, del Código Procesal Penal (1 de abril de 2008); Rol No 986: Requerimiento de inaplicabilidad por inconstitucionalidad respecto del artículo 387, inciso segundo, del Código Procesal Penal (30 de enero de 2008); Rol No 1130: Requerimiento de inaplicabilidad por inconstitucionalidad respecto del inciso segundo del artículo 387 del Código Procesal Penal (7 de octubre de 2008); Rol No 1432: Requerimiento de inaplicabilidad por inconstitucionalidad respecto de los artículos 364 y 372 a 387 del Código Procesal Penal y del artículo 390 del Código Penal (5 de agosto de 2010); Rol No 1443: Requerimiento de inaplicabilidad por inconstitucionalidad respecto de los artículos 364 y 372 a 387 del Código Procesal Penal, 1º 3o, 22 y 25 de la Ley No 20.000, 16, 17 y 19, letra a), del mismo cuerpo legal, y de los artículos $1^{\circ}, 15$, No $1^{\circ}, 7,50$ y 52 del Código Penal (26 de agosto de 2010) y Rol No 1501: Requerimiento de inaplicabilidad por inconstitucionalidad respecto del inciso segundo del artículo 387 del Código Procesal Penal (31 de agosto de 2010). 
de la evidencia rendida, la bilateralidad de la audiencia, la facultad de interponer recursos para revisar las sentencias dictadas por tribunales inferiores...", agregando "que, de este modo, el derecho al recurso no debe entenderse como sinónimo del derecho al recurso de apelación, sin perjuicio de lo cual esta Magistratura ha señalado que se ve afectada la igual protección de los derechos 'cuando un derecho procesal básico es otorgado por la ley a sólo uno de los agraviados por una resolución judicial, excluyendo al otro de la posibilidad de reclamar" 25 .

Asimismo, el Tribunal erradamente ha sostenido la imposibilidad del reexamen de los fallos emanados de tribunales orales: "que, por último, los principios de inmediación y oralidad impiden que se pueda 'hacer de nuevo' el juicio. La Cámara de Diputados consideró que la oralidad del procedimiento requiere que el tribunal que conoce el juicio tenga el máximo poder de decisión. Si, en vez de darle el poder de decisión final, salvo excepciones, al tribunal que asiste al juicio oral, se le otorga a otro tribunal, que conocerá de la causa por la vía de la lectura del expediente, se estaría poniendo el centro del debate en la lectura del expediente y no en el juicio oral. No sólo se pondría el énfasis en la lectura del expediente, sino que se terminaría privilegiando la opinión del tribunal menos informado por sobre la opinión del tribunal más informado'. A lo que agregó que él recurso de apelación, en el sentido de un tribunal de segunda instancia que conoce con la misma amplitud de competencia y con la misma capacidad de modificación de la sentencia de los tribunales de primera instancia, es un recurso propio del sistema inquisitivo y es completamente incompatible con el juicio oral' (Primer Informe de la Comisión de Constitución, Legislación y Justicia de la Cámara de Diputados). Por su parte, en el Senado la Comisión coincidió con el mérito de la propuesta, en orden a que no sea apelable la sentencia pronunciada por el tribunal de juicio oral. Pesó en su ánimo no sólo la composición del tribunal oral, sino el hecho de que éste habrá desarrollado su trabajo con sujeción a los principios de oralidad y de inmediación, y que aceptar la apelación importaría destruirlos, porque la Corte de Apelaciones, al conocer de ella, lo haría sobre la base de la escrituración, puesto que deberá estudiar los registros y actas de lo obrado, y de la mediación, toda vez que no tomará conocimiento directo y personal de la prueba. De esta manera, la reforma procesal penal sería sólo aparente, puesto que, por la vía de recurrir de apelación, la última decisión correspondería a un tribunal que seguiría resolviendo del mismo modo en que lo hace hoy dia' (Segundo Informe de la Comisión de Constitución, Legislación, Justicia y Reglamento del Senado)"26.

25 Sentencia del Tribunal Constitucional, de 5 de agosto de 2010, Rol № 1432.

26 Sentencia del Tribunal Constitucional, de 5 de agosto de 2010, Rol No 1432. 
Finalmente, se debe señalar que el Tribunal ha venido efectuando una interpretación restrictiva del contenido protegido por el derecho a recurrir o impugnar de un fallo agraviante, que claramente salta de manifiesto en los considerandos antes citados, pero que encuentran su punto más álgido en la doctrina que estableció en el caso de Aarón Vásquez, que sostuvo que si viene existen determinadas hipótesis donde el reexamen se encuentra prohibido "resultaría plenamente procedente el recurso de queja previsto en el artículo 545 del Código Orgánico de Tribunales, desde que dicha vía de impugnación es factible respecto de las faltas o abusos graves cometidos en la dictación de resoluciones de carácter jurisdiccional, en la especie, sentencia definitiva condenatoria y respecto de la cual no procede recurso alguno" 27. Con todo, dicha argumentación carece de un sustento lógico y adecuado, dada la naturaleza extraordinaria también del recurso de queja al igual que el recurso nulidad penal ${ }^{28}$, en efecto "en el caso de la sentencia comentada el tribunal Constitucional no tuvo en consideración la doctrina emanada de los fallos de la Corte Interamericana de Derechos Humanos sobre los alcances del derecho al recurso y la calidad del recurso"29.

\section{Argumentos que se esgrimen para el establecimiento de recursos "limitados" en sede procesal civil}

Se ha expuesto que el sistema clásico de la doble instancia civil, que se apertura con la interposición del recurso de apelación, ya no sería viable desde dos

\footnotetext{
27 Sentencia del Tribunal Constitucional, de 30 de enero de 2008, Rol No 986.

28 "Que las razones de buen uso de los recursos humanos y financieros de los que dispone el sistema judicial son desde luego relevantes para determinar las vías de impugnación de sentencias que pueda establecer un sistema, pues tales recursos serán siempre limitados. Por ello, garantizar ciertas vias de impugnación necesariamente implicará el uso de recursos humanos y financieros en ello, lo que afectará a lo menos la celeridad con que puedan ser atendidos otros procesos.

Sin embargo, estas consideraciones económicas no son suficientes para dotar de racionalidad o justicia la severa limitación que podría llegar a aplicársele al condenado que recurre en estos autos. Desde luego, porque esta finalidad, alegada en estrados, no aparece, como se acredita en la anterior disidencia, entre las razones consideradas por el legislador. Aunque las supusiéramos, ni en el debate legislativo ni las partes en estrados han entregado prueba o indicio alguno de que el buen funcionamiento del sistema procesal penal pudiera llegar a afectarse con la concesión de vias de impugnación en casos que, como el de la especie, siempre serán excepcionales. En tercer lugar, no resulta razonable pensar que efectivamente el buen uso de los recursos financieros y humanos del sistema procesal penal puedan verse afectados en caso que, por acogerse este requerimiento, llegara a concederse la vía de impugnación que reclama el requirente" (Sentencia del Tribunal Constitucional, de 30 de enero de 2008, Rol No 986, voto disidente).

29 Nogueira (2012), p. 373.
} 
puntos de vista. Primero, "si el enjuiciamiento de un mismo asunto por dos órganos diferentes ofrece una mayor garantía de seguridad y acierto que la labor de uno solo" 30 por qué no establecer un número superior a dos instancias que puedan conocer y resolver el conflicto de relevancia jurídica. Segundo, que si se sostiene como argumento el mayor grado de experiencia de los jueces miembros de los tribunales superiores de justicias "por qué no encomendar desde el principio, la decisión del proceso a esos órganos colegiados más expertos y mejor preparados"31_32 que dilatar el proceso y que éste sea primero resuelto por los jueces menos calificados para posteriormente subir a dichos órganos más experimentados. En dicha perspectiva, se debería eliminar el sistema tradicional de impugnación que se conoce hasta hoy respecto de las sentencias definitivas de primer grado de jurisdicción.

En síntesis, se ha venido señalando que la doble o única instancia o la existencia de un recurso amplio o restringido obedecerían a cuestiones meramente de técnica procesal, lo que es del todo errado; basta diferenciar los verdaderos principios de las reglas procesales y, asimismo, éstos de las reglas del sentencia que "presentan características similares a las ya vistas precedentemente respecto a la actividad de procesar: siempre binarias y se relacionan con distintos aspectos propios de la tarea de sentenciar: calidad y número de juzgadores, cantidad de grados de conocimiento, evaluación de los medios de confirmación, correspondencia entre lo pretendido y lo acordado en el juzgamiento y aplicación de la norma jurídica que rige al caso justiciable" 33 . En consecuencia, siendo el derecho al recurso una garantía de aquellas que comprende y protege la Constitución Política y su contenido impone el deber de establecer un mecanismo de impugnación que permita alzarse contra ambos errores que puede cometer la jurisdicción, el legislador queda constreñido y obligado al establecimiento de procesos que permitan varios grados

\footnotetext{
30 NúNÉEZ (2008), p. 212.

31 NúNÉEZ (2008), p. 212.

32 En la misma línea se ha dicho "es absolutamente cuestionable la creencia acrítica en el dogma del carácter cuasi sagrado de la apelación”, agregándose que si se reconoce la existencia de error judicial la apelación no es la única "siquiera la mejor" forma de corregirlo. Así, los autores plantean las siguientes interrogantes, si seguimos dicho argumento hasta el infinito: “¿Por qué entonces tener sólo dos instancias, y no tres o cuatro? ¿Cuál es el criterio por el cual decimos: 'dos veces está bien, pero tres es demasiado’? O si ya asumimos el carácter imperfecto de la jurisprudencia ¿Por qué no asumimos las limitaciones económicas y nos quedamos sólo con una?...", entre otras conjeturas que plantean los autores del artículo (LeTURIA; CAVIEDES (2011), pp. 404-405).

33 GonZÁlez (2004), p. 288.
} 
de jurisdicción, en el entendido que instancia constituye el momento jurisdiccional que permite analizar y controlar los hechos y el derecho.

\section{Sistema recursivo en el Proyecto de Código Procesal Civil}

El Mensaje del Ejecutivo parte por establecer un objetivo preciso y claro sobre el nuevo sistema recursivo, cual es, la "racionalización adecuada del sistema de impugnaciones". Lo anterior, sumado a la simplificación de la nomenclatura de las resoluciones judiciales y al sistema de ejecución provisional de los fallos llevan -derechamente- a proscribir prácticas dilatorias muy arraigadas en nuestro medio, desincentivando el uso de los medios de impugnación.

Asimismo, hace una alusión y reconocimiento expreso al derecho al recurso y aboga por el cumplimiento irrestricto a los tratados internacionales en la materia (y lo que las cortes de derechos humanos han señalado) así, "el Código realiza una reforma profunda al sistema recursivo actualmente vigente que refleja la simplicidad y eficiencia, a la vez que un justo equilibrio entre tales aspiraciones y el debido proceso".

En consecuencia, los mayores cambios en materia recursiva apuntan por el establecimiento de un recurso único contra la sentencia de primer grado de jurisdicción, pero con dos fines claramente diversos; pudiendo solicitarse que ésta se enmiende o revoque conforme a derecho o solicitar la invalidación del juicio y la sentencia o solamente de esta última. Además, se introduce un recurso extraordinario para ante la E. Corte Suprema, cuando se hubieren infringido en forma esencial derechos y garantías aseguradas en la Constitución Política del Estado o por los tratados internacionales ratificados y que se encuentren vigentes, o en caso que la Corte estimare pertinente fijar, uniformar, aclarar o modificar una doctrina jurisprudencial.

La novedad está dada por la fusión en un solo arbitrio procesal del actual recurso de apelación y del recurso de casación en la forma, que pasará a ser de competencia exclusiva de las Cortes de Apelaciones. Lo anterior tiene como base lo expuesto en los artículos 379 y 381 del Proyecto, donde se señala el objeto del recurso de apelación y las causales específicas del mismo. Asimismo, el recurso extraordinario procederá contra las sentencias definitivas e interlocutorias, inapelables, que pongan término al juicio o hagan imposible su continuación, dictadas por una Corte de Apelaciones (art. 406 del Proyecto), transformándose en una suerte de casación en el fondo, que establece un verdadero certiorari, ya que la Corte Suprema determinará avocarse al conocimiento del asunto de que se trate 
cuando la mayoría de los miembros de la sala respectiva estimen que concurre un interés general que haga necesaria su intervención.

En cuanto al recurso de apelación, el Mensaje, anticipándose a la crítica (cada vez más álgida en la materia) señala que "se establece (un) sistema recursivo con amplitud suficiente, a través del recurso de apelación, para controlar el proceso de formación de convicción del juez y el cumplimiento de los parámetros que impone la sana crítica para el establecimiento de los hechos que han requerido de prueba" (sic) agrega, que "en cumplimiento de los tratados internacionales y la interpretación de las cortes internacionales sobre el contenido del 'derecho al recurso', se consagra un recurso de apelación amplio, con revisión por el tribunal superior tanto de los hechos como del derecho, pero sin que ello importe la repetición de una nueva instancia o grado jurisdiccional que ha pasado a ser el concepto sustituto, en el cual se contemple la reanudación del debate y nuevas pruebas" 34 .

De esta forma, en el espíritu del Mensaje y en el articulado respectivo se observa un cumplimiento adecuado de los estándares del derecho al recurso que hemos precitado ${ }^{35}$. En síntesis, se establece un recurso amplio y de mérito que posibilita un reexamen del material fáctico y del derecho. Ahora bien, necesario es hacer la prevención de que la práctica judicial, en lo que dice relación con la admisibilidad ${ }^{36}$ y resolución de fondo, no genere consecuencias perniciosas para los derechos del justiciable, como lo que se ha visto hasta hoy en materia de recursos de nulidad penal y laboral: excesivo formalismo, dilaciones, proliferación de recursos disciplinarios, etc.

No compartimos eso sí, ya que apunta más una simplificación técnica que práctica, la fusión del recurso de apelación con el recurso de casación en la forma, ya que representa una desnaturalización de la apelación y su fin clásico (la enmienda conforme a derecho), ampliándose a la invalidación del juicio y la sentencia, o solamente de esta última, cuando concurren las causales establecidas.

\footnotetext{
34 Proyecto de Nuevo Código Procesal Civil (Boletín No 8197-07), pp. 22-23.

35 Señala el artículo 379, como objeto del recurso: "El recurso de apelación tiene por objeto obtener del tribunal superior respectivo, que enmiende o revoque conforme a derecho la resolución del inferior, total o parcialmente, con base precisa en las pretensiones, excepciones o defensas formuladas en su caso, ante el tribunal inferior.

Podrá alegarse además, o bien exclusivamente, la infracción a normas que consagren derechos o garantias procesales cometidas en primer grado jurisdiccional, para obtener la invalidación del juicio y de la resolución respectiva o solamente de ésta, y ello por las causales especificas señaladas en este Título. En este último caso el recurrente expresará en capitulos separados los motivos que justifiquen la enmienda o revocación, de aquellos que justifiquen la invalidación del juicio y de la resolución respectiva o sólo de ésta. Con todo, la pretensión de enmienda o revocación, sólo se podrá hacer valer en subsidio de la de invalidación".

36 Ver, por ejemplo, lo sucedido en materia laboral en Palomo; Valenzuela (2011), pp. 399-415.
} 